\title{
Facile Colorimetric Determination of Duloxetine in Formulations Using Methyl Orange as Ion-Pairing Agent
}

\author{
Pushparaj Hemalatha ${ }^{1,2}$, Mani Ganesh ${ }^{1,2}$, Mei Mei Peng ${ }^{1,2}$ and Hyun Tae Jang ${ }^{1,2^{\star}}$ \\ ${ }^{1}$ Department of Chemical Engineering, Hanseo University, ${ }^{2}$ Korea Carbon Capture \& Sequestration R\&D Centre, 360 Daegok- \\ ri, Haemi-myun, Seosan-si 356 706, Chungcheongnam-do, South Korea
}

*For correspondence: Email: htjang@hanseo.ac.kr; Tel.: +82-41-660-1423

\begin{abstract}
Purpose: To develop a new and fully validated ion-pair spectrophotometric method for the determination of duloxetine hydrochloride (DX).

Methods: Ion-pair spectrophotometric method was employed for the determination of duloxetine hydrochloride (DX) in bulk and pharmaceutical formulations using acidic dye methyl orange (MO) as ion-pairing agent at pH 4 (phthalate buffer). The yellow ion-pair complex was extracted with chloroform and spectrophotometrically estimated at $420 \mathrm{~nm}$. The developed method was validated according to $\mathrm{ICH}$ and USP guidelines.

Results: The ion-pair complex of DX and MO obeyed Beer's law in the range of $2-20 \mu g \mathrm{~mL}^{-1}$ of $D X$ with a correlation coefficient of 0.998 . Recovery was good, with a relative standard deviation (\%RSD) of 0.88 - 1.02; precision (inter-day, 0.878 and intra-day, 0.921) was also within validation limits. The limit of detection (LOD) and limit of quantitation (LOQ) were 0.25 and $4 \mu \mathrm{g} \mathrm{mL^{-1 }}$, respectively. The method developed was successfully applied to determine DX in a formulation.

Conclusion: The developed method is accurate, precise, rugged, robust and reproducible. It is also sensitive and specific for the determination of DX in bulk and formulation.
\end{abstract}

Keywords: Duloxetine, Methyl orange, Ion-pair, Validation, Spectrophotometry

Tropical Journal of Pharmaceutical Research is indexed by Science Citation Index (SciSearch), Scopus, International Pharmaceutical Abstract, Chemical Abstracts, Embase, Index Copernicus, EBSCO, African Index Medicus, JournalSeek, Journal Citation Reports/Science Edition, Directory of Open Access Journals (DOAJ), African Journal Online, Bioline International, Open-J-Gate and Pharmacy Abstracts

\section{INTRODUCTION}

Duloxetine hydrochloride (DX) is chemically $((+)-$ (S)-N-methyl-3-(1-naphthalenyloxy)-2-thiophene propanamine) hydrochloride (Fig 1.). Recently, DX was approved by United States Food and Drug Administration (US FDA) as a balanced selective serotonin and nor-epinephrine reuptake inhibitor and is used in the treatment of major depressive disorders and diabetic peripheral neuropathic pain [1-3].

The literature on analytical methods for DX revealed that it has been determined by high performance liquid chromatography (HPLC) [46], high performance thin layer chromatography<smiles>ClC(Cl)CC[C@H](Oc1cccc2ccccc12)c1cccs1</smiles>

Figure 1: Structure of $D X$

(HPTLC) [7,8], liquid chromatography-tandem mass spectroscopy (LC-MSMS) [9], ultraviolet (UV) spectrophotometric [10] and colorimetric 
methods [11,12]. Recently extractive colorimetric methods using bromocresol green, bromothymol blue and bromophenol blue as ion-paring chromogens was studied but only partially validated [11,12]. In general, extractive colorimetric procedures are popular for their sensitivity and selectivity towards the active component of interest $[13,14]$. Due to the ease of this technique, it can be considered for the quantitative determination of many pharmaceuticals.

To the best of our knowledge, there are no previous reports on the determination of DX using methyl orange (MO) as ion-pairing agent. Therefore, in the present study, an ion-pair extractive spectrophotometric quantitative analysis of DX using MO was undertaken. The main aim was to develop a simple, accurate, precise extractive colorimetric method for the determination of DX and validate its suitability for assaying the DX content of formulations according to the requirements of United States Pharmacopeia (USP) and International Conference on Harmonization $(\mathrm{ICH})$ guidelines for method validation $[15,16]$.

\section{EXPERIMENTAL}

\section{Chemicals and reagents}

All chemicals were of analytical reagent grade procured from Daejung Chemicals \& Metals, Gyeonggi-do, South Korea. Doubly distilled water was used to prepare all solutions. Freshly prepared solutions were used for method development and validation. Potassium hydrogen phthalate buffer solution ( $\mathrm{pH} \mathrm{4)}$ was prepared by standard procedure. Methyl orange (MO, 0.1 $\% w / v)$ was prepared in hot water. Standard duloxetine hydrochloride (DX) was obtained from Sigma Aldrich and tablets containing $60 \mathrm{mg}$ duloxetine (Cymbalta, Eli Lilly and Company) were purchased from a retail pharmacy.

\section{Instrumentation}

A Shimadzu UV mini-1240 UV-Visible spectrophotometer with $1 \mathrm{~cm}$ quartz cells was used for all spectral measurements with Shimadzu UV Probe system software (version 2.1). $\mathrm{pH}$ measurements were carried out using a calibrated digital $\mathrm{pH}$ meter (Neomet pH-200L, Seoul, South Korea).

\section{Standard solution of the drug}

A stock solution of $1 \mathrm{mg} \mathrm{mL}^{-1}$ was prepared by dissolving DX in alcohol (99 \%). Working standards were prepared by suitable dilution of the standard stock solution.

\section{Sample preparation}

From the $100 \mu \mathrm{g} \mathrm{mL}^{-1}$ working standard solution, aliquots were transferred to a series of $100 \mathrm{ml}$ separating funnels and $1 \mathrm{~mL}$ of buffer $(\mathrm{pH}$ 4) and $1 \mathrm{~mL}$ of $0.1 \% \mathrm{w} / \mathrm{v} \mathrm{MO}$ was added to each separating funnel and shaken well followed by the addition of $10 \mathrm{~mL}$ of chloroform. The contents were shaken well and kept aside to allow for separation. The chloroform layer was separated and passed through previously dried anhydrous sodium sulphate to remove the water in the organic layer.

\section{Determination of maximum absorbance $\left(\lambda_{\max }\right)$ and linearity}

Absorption spectrum of the yellow DX-MO ionpair complex was obtained by scanning the chromogen extracted using chloroform from 350 - 600 nm. To determine Beer's law limit, a calibration curve was constructed by plotting absorbance against concentration.

\section{Validation of the method}

For routine use of the method, optimization was carried out for rapid and quantitative formation of colored ion-pair complexes by a number of preliminary experiments. USP [15] and ICH [16] guidelines were followed for method validation.

\section{$\angle O D$ and $L O Q$}

The limit of detection (LOD) and limit of quantitation (LOQ) of the method was established using the formula: $L O D$ or $L O Q=K$ SD $a / b$, where $\mathrm{K}=3$ for LOD and 10 for $L O Q$, while SD is standard deviation with intercept (a) and slope $(b)$ of the standard graph.

\section{Precision}

Intra-day precision was calculated by estimating the \%RSD of DX solution (12 $\left.\mathrm{gg} \mathrm{mL}^{-1}\right)$ at various time intervals (5 times) on the same day, while the inter-day precision was calculated by estimating the \%RSD of DX solution $\left(12 \mu \mathrm{g} \mathrm{mL}{ }^{-1}\right)$ on five consecutive days

\section{Accuracy}

Accuracy expresses the agreement between the established value and the true value. This was achieved by recovery studies, i.e., spiking a known quantity of pure drug to a pre-analyzed sample and the proposed analysis procedure was followed. 
Application of the developed method to formulations

Twenty commercial DX tablets were weighed and the mean tablet weight was calculated before they were ground to fine powder. A known quantity of the powder was accurately weighed and transferred into a $50 \mathrm{~mL}$ volumetric flask. The volume was made up to mark with alcohol, shaken well and filtered through Whatman filter paper no. 40. Suitable aliquots of this solution were taken for the assay of DX.

\section{Interference and placebo study}

Studies on interference by common excipients that might be used in formulations were carried out by mixing a known amount of DX $(60 \mathrm{mg})$ with specified amounts of the common excipients such as lactose, starch and talc in their recommended proportions [15]. The analysis of these mixtures was carried out using the above procedure and the recovery values for DX were determined. Likewise, the mixture of above excipients was prepared but without the drug, and the same procedure was used for analysis.

\section{Robustness and ruggedness}

Robustness (effect of deliberate change in analytical parameters) was studied by determining the amount of DX in the tablets by slightly varying the wavelength of determination and the dye's (MO) concentration. Ruggedness was established by determining DX in the tablet formulation using two different spectrophotometer Shimadzu UV mini-1240 (system I) and SCINCO, Neosys-2000 DRS-UV provided with liquid sample analysis port (system II) and two different analysts (I and II). The results obtained were within the recommended $\%$ RSD limit (<2\%).

\section{Study of bench top stability of chromogen}

To study the stability of chromogen, a specified quantity of stock solution $\left(1 \mathrm{mg} \mathrm{mL}^{-1}\right)$ was mixed with the above standardized quantity of buffer and $\mathrm{MO}$, kept aside (10 $\mathrm{min})$ for reaction and extracted with chloroform.

\section{RESULTS}

\section{Solvent and buffer}

From the trials, potassium hydrogen phthalate buffer was found to be suitable and chloroform was chosen as the most suitable solvent for extraction among those tested which included carbon tetrachloride, dichloromethane and diethyl ether. The suitability of chloroform for extraction of ion-pair has also been reported by other researchers [11-14]. A volume of $1 \mathrm{~mL}$ of MO $(0.1 \% \mathrm{w} / \mathrm{v})$ was found to be optimal for complete complexation.

\section{Maximum absorbance $\left(\lambda_{\max }\right)$}

The full scan spectra of DX-MO complex showed maximum absorbance at $420 \mathrm{~nm}$ (Fig 2a). Figure $2 b$ indicates that the formed complex

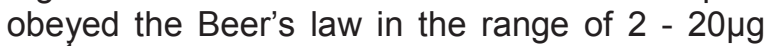
$\mathrm{mL}^{-1}$. The regression equation for the results was $y=0.0515 x-0.1052(r=0.9987)$. The molar absorptivity $(\Theta)$ was $1.3967 \times 10^{4} \mathrm{~L} \mathrm{~mol}^{-1} \mathrm{~cm}^{-1}$ and Sandell's sensitivity $0.02390 \mu \mathrm{g} \mathrm{cm}^{-2} / 0.001$ abs unit.
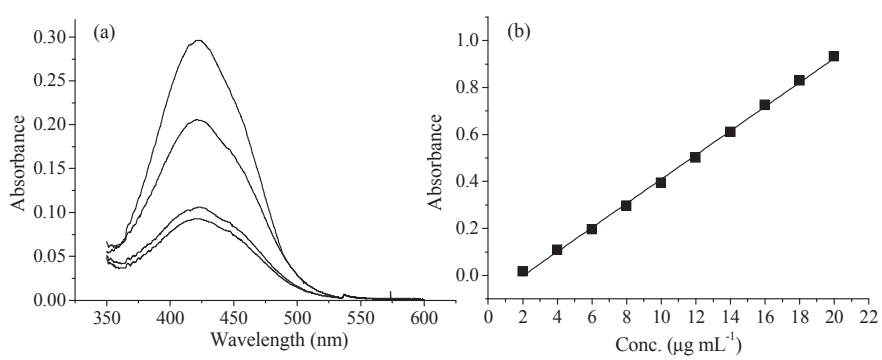

Figure 2: (a) Overlay spectra of DX-MO ion-pair complex (b) Linearity plot

\section{Bench top stability of chromogen}

The absorbance of the chromogen from the time of extraction (considered as $0 \mathrm{~min}$ ) to various time intervals was determined and the results plotted as absorbance against time (plot not shown). The plot shows that the chromogen was stable up to $3.5 \mathrm{~h}$.

\section{Stoichiometry of the reaction}

The drug-dye (DX-MO) stoichiometric ratio was calculated by Job's continuous variation method and it was found that DX and MO formed a 1:1 complex [17].

\section{LOD and LOQ}

LOD and LOQ were 0.25 and $4 \mu \mathrm{g} \mathrm{mL} \mathrm{m}^{-1}$, respectively. The low values indicate the high sensitivity of the proposed method.

\section{Assay}

The assay results for the marketed formulation (tablets) by the proposed and UV (standard) methods [10] were 99.95 and $99.98 \%$, respectively, of the label claim. No significant differences were found between the calculated and theoretical values, based on $t$ - and $F$-tests at 
Table 1: Assay data

\begin{tabular}{|c|c|c|c|c|c|c|}
\hline \multirow{2}{*}{$\begin{array}{l}\text { Label claim } \\
\text { (mg/tab) }\end{array}$} & \multicolumn{2}{|c|}{$\%$ Amount $^{\mathrm{a}}$} & \multicolumn{2}{|c|}{$\%$ RSD $^{a}$} & \multicolumn{2}{|c|}{ Confidence } \\
\hline & Proposed & Reported & Proposed & Reported & $t$-test ${ }^{b}$ & $F$-test $^{b}$ \\
\hline 60 & 99.95 & 99.98 & 0.18 & 0.20 & 1.4 & 2.9 \\
\hline
\end{tabular}

Table 2: Precision and accuracy

\begin{tabular}{|c|c|c|c|c|c|}
\hline \multirow{2}{*}{ Conc. $\left(\mu \mathrm{g} \mathrm{mL}^{-1}\right)$} & \multicolumn{2}{|c|}{ Precision } & \multicolumn{3}{|c|}{ Accuracy } \\
\hline & Inter-day & Intra-day & \% Spike level & $\%$ Recovery ${ }^{a}$ & $\% R S D^{a}$ \\
\hline & $\% R S D^{a}$ & $\% R S D^{a}$ & 75 & 100.1 & 1.02 \\
\hline 12 & 0.878 & 0.921 & 100 & 99.83 & 0.88 \\
\hline & & & 125 & 99.93 & 0.97 \\
\hline
\end{tabular}

a Mean of five determinations

95\% confidence level, which proves that the proposed method is comparable with that of reference (standard) method (Table 1).

\section{Precision and accuracy of the method}

The results obtained for precision of the method are given in Table 2 . The relative standard deviation (\%RSD) was low, being 0.878 and $0.921 \%$ for inter- and intra-day precision, respectively, and thus indicates high precision (repeatability) of the method. Recovery data are also presented in Table 2. Mean \%RSD determined at three levels was in the range 0.88 - $1.02 \%$, indicating good accuracy of the proposed method.

\section{Effect of MO concentration and volume}

The effect of concentration of MO was studied by measuring the absorbance of solutions containing DX $\left(12 \mu \mathrm{g} \mathrm{mL}^{-1}\right), 1 \mathrm{~mL}$ of buffer and $1 \mathrm{~mL}$ of $\mathrm{MO}$ solution at various concentration (0.05 - 0.175 $\% \mathrm{w} / \mathrm{v})$. The results are depicted in Fig 3a. MO concentration of $0.1 \% \mathrm{w} / \mathrm{v}$ gave maximum absorbance and it was therefore chosen as most suitable for complexation.

The effect of the volume of MO was studied by varying the volume of the added dye $(0.5-2 \mathrm{~mL})$ while maintaining dye concentration at $0.1 \% \mathrm{w} / \mathrm{v}$ and drug concentration at $12 \mathrm{\mu g} \mathrm{mL}^{-1}$ (Fig 3b). The results show that $1 \mathrm{~mL}$ of $0.1 \% \mathrm{w} / \mathrm{v} \mathrm{MO}$ was enough to form complex as it produced maximum absorbance. Larger volumes of reagent had no marked effect on ion-pair complex formation.

\section{Effect of $\mathrm{pH}$}

The effect of $\mathrm{pH}$ was studied by analyzing a solution containing DX $\left(12 \mu \mathrm{g} \mathrm{mL}{ }^{-1}\right), 1 \mathrm{~mL}$ of 0.1
$\% \mathrm{w} / \mathrm{v} \mathrm{MO}$ and $1 \mathrm{~mL}$ of buffer of varying $\mathrm{pH}$ of 3.8 4.2. The results showed that $1 \mathrm{~mL}$ of buffer with $\mathrm{pH} 4$ was suitable for the determination of $\mathrm{DX}$.
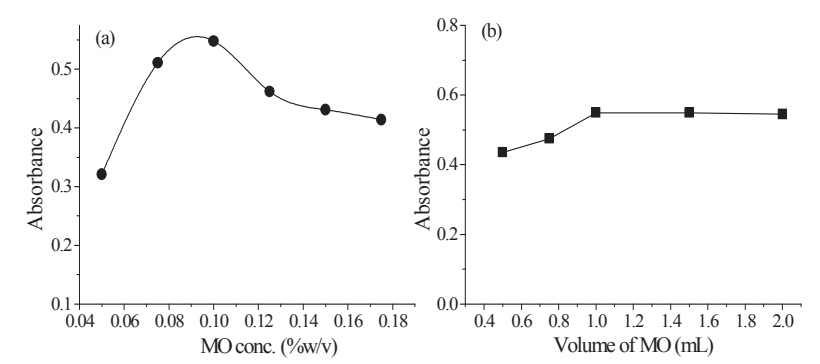

Figure 3: Plot of absorbance vs. (a) MO concentration and (b) MO volume

\section{Interference and placebo influence}

The effect of excipient (lactose, starch and talc) interference with the proposed method showed that recovery of the drug was $100.09 \pm 0.78$, $99.95 \pm 0.60$ and $99.58 \pm 0.50$, respectively. Since recovery of the drug was high, it therefore means that the added excipients had no significant effect on the assay. Absence of color in the extract obtained from the placebo indicates the selectivity of the method.

\section{Robustness and ruggedness}

As Table 3 shows, the results obtained were within the recommended limits for \%RSD (<2\%).

\section{DISCUSSION}

Anionic MO forms an ion-association complex with the positively charged quaternary amine of DX. The DX-MO complex is a pair of two oppositely charged ions of single unit held together by an electrostatic force of attraction. 
Table 3: Robustness and ruggedness of the developed method

\begin{tabular}{|c|c|c|c|c|c|c|c|}
\hline \multicolumn{4}{|c|}{ Robustness } & \multicolumn{4}{|c|}{ Ruggedness } \\
\hline $\begin{array}{c}\text { Wavelength } \\
\text { (nm) }\end{array}$ & $\% R S D^{a}$ & $\begin{array}{c}\text { MO conc. } \\
(\% w / v)\end{array}$ & $\% R S D^{a}$ & Analyst & $\% R S D^{a}$ & System & $\% R S D^{a}$ \\
\hline 419 & 0.342 & 0.09 & 0.546 & I & 0.125 & I & 0.156 \\
\hline 421 & 0.421 & 0.11 & 0.798 & II & 0.752 & II & 0.963 \\
\hline
\end{tabular}

${ }^{a}$ Mean of five determinations

The formed yellow ion-pair complex showed maximum absorbance at $420 \mathrm{~nm}$ and obeyed.

Beer's law in the concentration range of $2-20$ $\mu \mathrm{g} \mathrm{mL} \mathrm{m}^{-1}$ with a very good correlation co-efficient of 0.9987 . The developed method was validated for its accuracy, precision, stability, ruggedness and robustness. All the studied parameters were within limits for validation of analytical methods, as prescribed in USP and $\mathrm{ICH}$ guidelines with respect to \%RSD. Furthermore, the interference study showed that the method was not affected by common excipients used in the study. The proposed method, therefore, is in good agreement with previously reported methods.

\section{CONCLUSION}

The developed ion-pair extractive colorimetric method for the determination of DX in bulk and in tablet formulation is sensitive, specific and rapid. The method also showed good accuracy and was selective for the drug. Since the developed method utilizes simple reagents, it should easily be affordable by most analytical laboratories. The developed method is thus recommended for routine determination of $\mathrm{DX}$ in tablet formulations validation.

\section{ACKNOWLEDGEMENT}

The authors acknowledge financial support for this work through grants from Korea CCS R\&D Centre, which is funded by the Ministry of Education, Science and Technology of the Korean Government.

\section{REFERENCES}

1. Goodman L, Gilman A. The Pharmacological Basis of Therapeutics. $11^{\text {th }}$ edition, New York, USA: McGraw Hill Publishers, 2005; p 436. 2. Hunziker MME, Suehs BT, Bettinger TL, Crisrnon
$M L$. Duloxetine hydrochloride: A new dualacting medication for the treatment of major depressive disorder. Clin Ther 2005; 27(8): 1126-1143.

3. Westanmo $A D$, Gayken J, Haight R. Duloxetine: $A$ balanced and selective norepinephrine- and serotonin-reuptake inhibitor. Am J Health Syst Pharm 2005; 62: 2481-2490.

4. Patel SK, Patel NJ, Patel KM, Patel PU, Patel BH. Estimation of duloxetine hydrochloride in pharmaceutical formulations by RP-HPLC method. Indian J Pharm Sci 2008; 70(6): 825827.
5

(1)

6.

Soni $P$. $P$, Mariappan TT, Banerjee UC. Highperformance liquid chromatographic method for the simultaneous estimation of the key intermediates of duloxetine. Talanta 2005; 67(5): 975-978.

7. Dhaneshwar SS, Deshpande P, Patil M, Vadnerkar G, Dhaneshwar SR. Development and validation of a HPTLC method for estimation of duloxetine hydrochloride in bulk drug and in tablet dosage form. Indian J Pharm Sci 2008; 70(2): 233-236.

8. Shahnawaz S, Siddiqui AW, Masroor MT, Arora V. Stability-indicating HPTLC method for determination of duloxetine hydrochloride in bulk drug and tablet formulation. Chromatogr Res Int 2011; Article ID 404189.

9. Selvan PS, Gowda KV, Mandal U, Solomon WDS, $\mathrm{Pal}$ TK. Determination of duloxetine in human plasma by liquid chromatography with atmospheric pressure ionization-tandem mass spectrometry and its application to pharmacokinetic study. J Chromatogr B 2007; 858(1-2): 269-275.

10. Yunoos $M$, Sankar DG, Kumar BP, Hameed $S$, Hussain A. Simple UV spectrophotometric determination of duloxetine hydrochloride in bulk and in pharmaceutical formulations. $E J$ Chem 2010; 7(3): 785-788.

11. Thangabalan B, Kalyani G, Yamini A, Kumar GA. Extractive spectrophotometric estimation of duloxetine hydrochloride in pure and in pharmaceutical formulations. IJPI's J Anal Chem 2011; 1(3): 30-34.

12. Susmitha $K$, Venkateswarlu G. Extractive spectrophotometric methods for determination of duloxetine hydrochloride in pharmaceutical formulations using acidic triphenyl methane dyes. Int J Chem Tech Res 2011; 3(3): 12461254.

13. Ganesh M, Thangabalan B, Patil R, Ganguly S, Sivakumar T. Simple extractive colorimetric determination of oxaprozin by acid-dye complexation methods in solid dosage form. $E$ J Chem 2008; 5(3): 593-597.

14. Ganesh M, Antony GJ, Saravankumar A, Rajesh R, Rajasekar K. A new validated spectrophotometric method for determination of trimetazidine in formulation and comparison with UV method. Der Pharma Chemica 2009; 1(2): 97-104.

15. The United States Pharmacopeia, The National Formulary 19, US Pharmacopeial Convention Inc., Rockville, MD 2000.

16. $\mathrm{ICH}$, Validation of analytical procedures: Text and methodology Q2 (R1), International Conference on Harmonization, Geneva, November 1996.

17. Job P. In Advanced Physicochemical Experiments; Oliner, Boyd, $2^{\text {nd }}$ edn, Edinburgh, UK, 1964; $p$ 54.

Trop J Pharm Res, February 2013;12 (1): 97 